Ambiente \& Água - An Interdisciplinary Journal of Applied Science
ISSN 1980-993X - doi:10.4136/1980-993X
www.ambi-agua.net
E-mail: ambi.agua@gmail.com

\title{
O papel dos comitês de bacia nos processos de licenciamento ambiental: um estudo de caso do comitê de bacia do rio Sorocaba e Médio Tietê (SP)
}

\author{
doi:10.4136/ambi-agua.2007
}

Received: 16 Nov. 2016; Accepted: 18 Oct. 2017

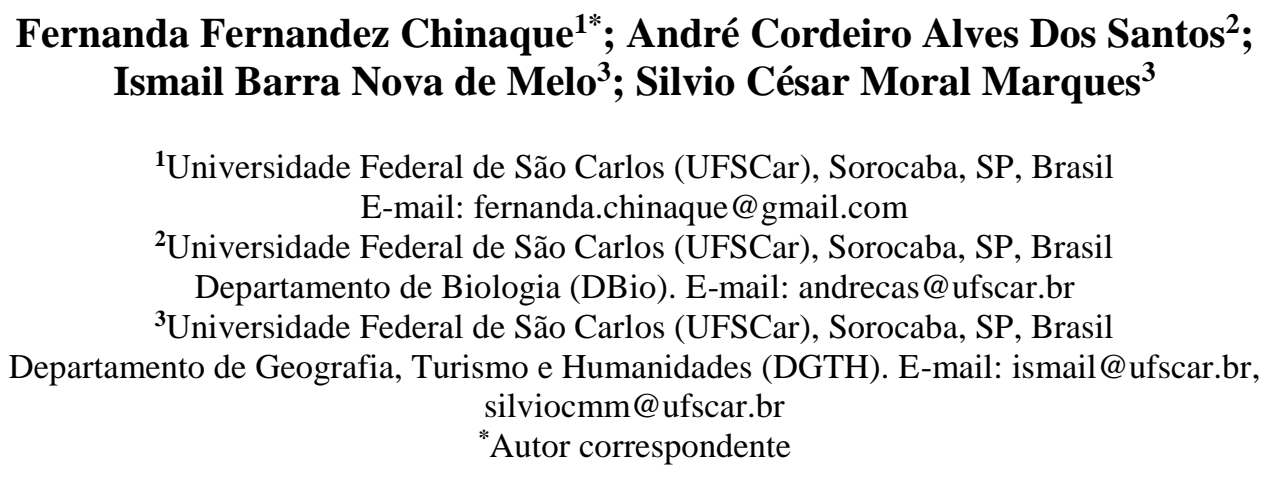

\section{RESUMO}

Uma das funções dos CBHs é promover discussões sobre os possíveis impactos ambientais e socioambientais de empreendimentos que pretendem estabelecer-se na região da Bacia Hidrográfica. Entretanto, qual é o impacto do comitê nesses processos de licenciamento ambiental? Eles assumem o seu papel nos processos de aplicação de políticas públicas voltadas para a proteção das águas? Com o objetivo de contribuir para o entendimento da participação dos CBHs nos processos de licenciamento ambiental, de empreendimentos impactantes aos recursos hídricos, a presente pesquisa adotou como estudo de caso o comitê de Bacia Hidrográfica do Rio Sorocaba e Médio Tietê, e utilizou como ferramenta de análise os documentos de três processos de licenciamento ambiental de Aterros Sanitários que passaram pelo CBH-SMT. Nos casos dos Aterros com localização nos municípios de Sorocaba/SP e Iperó/SP, o órgão licenciador ignora as posições do comitê. Em relação ao Aterro com localização em Araçariguama/SP, o órgão referencia o comitê em poucos pontos de sua manifestação, e na maioria, contrário às posições do comitê. As reflexões dos resultados sugerem que o poder do comitê é minimizado nas análises de EIA, se comparado à proposta de gestão descentralizada e democrática das águas no Brasil. Entretanto, eles podem estar contribuindo para a inquietação da população e estimulando seu protagonismo nas tomadas de decisão. Ainda assim, os CBHs não devem se contentar como estimuladores da população, mas sim buscar seu fortalecimento para tornarem-se instrumentos de aplicação de políticas públicas voltadas para a proteção dos recursos hídricos.

Palavras-chave: gestão de bacias hidrográficas, proteção das águas, políticas públicas, CBH-SMT. 


\title{
The role of basin committees in environmental licensing processes: a case study of the Sorocaba and middle Tietê river basin committee
} (SP)

\begin{abstract}
One of the functions of CBHs is to promote discussions with the possible environmental and socio-environmental impacts of enterprises that want to establish in Basin regions. However, what is the impact of the committee on these environmental licensing processes? Is their role in public policy implementation processes aimed the protection of the waters? In order to contribute to the understanding of the role of $\mathrm{CBHs}$ in environmental licensing of enterprises with impact on water resources, this research conducted a case study of the Watershed Committee of the Sorocaba River and Middle Tietê, and used documents of three environmental licensing procedures for landfills that have gone through CBH-SMT as analysis tools. Regarding the landfills located in the cities of Sorocaba/SP and Iperó/SP, the licensing agency ignores Committee positions. Regarding the landfill at Araçariguama/SP, the agency references the committee at some places in the documentation, but most of these contradict the Committee's position. The results of the EIA analysis suggest that the power of the Committee is minimized and do not followthe proposed decentralized and democratic water management in Brazil. However, they may be contributing to the restlessness of the population and encouraging their active involvement in decision-making. However, CBHs should not be used merely as stimulators of public opinion, but should be empowered as instruments of public policies for the protection of water resources.
\end{abstract}

Keywords: watershed management, water protection, public policy, CBH- SMT.

\section{INTRODUÇÃO}

A política Nacional e Estadual de recursos hídricos criou os Comitês de Bacias Hidrográficas (CBHs), que são importantes espaços democráticos, de poder deliberativo e consultivo, composto por diferentes atores que buscam um consenso sobre os múltiplos interesses e usos da água na bacia.

Os comitês representam de maneira espelhada a Política dos recursos hídricos, de forma que "o êxito de seu funcionamento, em certa medida, significa o êxito da própria política das águas" (Cardoso, 2003, p.1), já que a essência descentralizadora, democrática, e estratégica da Política, devem ser praticadas dentro dos colegiados.

Uma das funções dos CBHs é promover discussões sobre os possíveis impactos ambientais (IA) e socioambientais de empreendimentos que pretendem estabelecer-se na região da Bacia. O território do Estado de São Paulo divide-se em 22 Unidades de Gerenciamento de Recursos Hídricos (UGRHI). A UGRHI 10, gerida pelo Comitê de Bacia Hidrográfica do Rio Sorocaba e Médio Tietê (CBH-SMT), conta com várias Câmaras Técnicas. Dentre elas, a Câmara Técnica de Planejamento e Gestão dos Recursos Hídricos (CTPLAGRHI) é responsável por discutir e analisar os EIA/RIMAs (Estudos de Impacto Ambiental e Relatórios de Impacto Ambiental) de possíveis empreendimentos a serem implantados dentro da sua Unidade. As análises e discussões resultam em um parecer técnico que posteriormente passa por aprovação em Plenária do CBH.

O CBH-SMT foi criado em 1995 com intenso apoio da Sociedade Civil. Este é integrado por 35 municípios com sede na bacia e com área de outros 18 e subdividido em seis subbacias: Médio Tietê Superior, Médio Tietê Médio, Médio Tietê Inferior, Alto Sorocaba, Médio Sorocaba e Baixo Sorocaba (Carvalho, 2011). A composição do colegiado dos comitês do Estado de São Paulo é tripartite, dividida igualmente entre representantes do Estado, dos 
municípios e da Sociedade Civil (São Paulo, 1991). No CBH-SMT são 18 membros titulares e 18 suplentes de cada segmento.

Além da (CTPLAGRHI), o CBH-SMT conta com mais cinco Câmaras Técnicas: Câmara Técnica da Cobrança pelo Uso da Água - CTCob; Câmara Técnica de Eventos e Educação Ambiental - CTEEA; Câmara Técnica de Proteção das Águas; Câmara Técnica de Planejamento Florestal - CTPLANFLOR; Câmara Técnica de Saneamento - CTSAN.

A Lei 6.938/81 (Política Nacional do Meio Ambiente) prevê o Estudo de Impacto Ambiental como importante instrumento de gestão, podendo ser solicitado quando obras ou atividades, tanto públicas quanto privadas, são consideradas de significativa degradação ambiental (as obras e atividades consideradas como degradantes ambientais são definidas pelo próprio órgão), (Brasil, 1981).

O CONAMA (Conselho Nacional de Meio Ambiente), o órgão competente por estabelecer normas e regras para o licenciamento de atividades potencialmente e efetivamente poluidoras, emitiu uma Resolução - 001/86 - que define impacto ambiental como:

(...) qualquer alteração das propriedades físicas, químicas e biológicas do meio ambiente, causada por qualquer forma de matéria ou energia resultante das atividades humanas que, direta ou indiretamente afetam:

I - a saúde, a segurança e o bem-estar da população;

II - as atividades sociais e econômicas;

III - a biota;

IV - as condições estéticas e sanitárias do meio ambiente;

V - a qualidade dos recursos ambientais (Conama, 1986, p. 1).

Uma vez que ambientes degradados são extremamente difíceis em voltar ao seu estado original, e que as técnicas que promovem esse retorno despendem muita energia e mostramse por vezes mais caras que a sua proteção, o EIA auxilia no controle prévio das alterações que possam surgir no ambiente local ou do entorno, provenientes das atividades e da implantação de empreendimentos, podendo evitar sua degradação e futura recuperação (Brasil, 2009).

Os CBHs possuem papel fundamental no processo de licenciamento ambiental, pois sua estrutura permite que análises técnicas, tanto nos aspectos ambientais, quanto nos sociais, possam ser feitas a partir dos estudos e relatórios de impacto ambiental, trazendo resoluções de problemas mais igualitárias e democráticas, que evitem que empreendimentos e atividades na região da Bacia, afetem o bem estar socioambiental da população, e principalmente a qualidade e quantidade da água.

Em 28 de outubro de 2008 o Conselho Estadual de recursos hídricos de São Paulo (CRH) emitiu uma deliberação ( $\left.\mathrm{n}^{\circ} 87\right)$ disciplinando a análise de EIAs pelos comitês, estabelecendo que um dos papéis dos $\mathrm{CBHs}$ é elencar condicionantes e medidas mitigadoras adicionais às já previstas nos EIAs, não sendo sua função, portanto, analisar a viabilidade dos empreendimentos (CRH, 2008). Os pareceres aprovados nas reuniões ordinárias dos comitês são enviados ao órgão licenciador, esclarecendo a posição do comitê em relação aquele empreendimento, e dessa forma as solicitações feitas pelo comitê podem ser repassadas aos empreendedores (caso o órgão julgue pertinente considerá-las).

A grande questão é: qual é a influência do comitê nesses processos de licenciamento ambiental? Associada a esta problemática, outros questionamentos devem ser levantados em sua relação com os processos de licenciamento ambiental: a) Efetivo papel que o comitê assume nos processos de aplicação de políticas públicas voltadas à proteção dos recursos hídricos; b) Atuação do comitê tem caráter consultivo, podendo o órgão licenciador acatar ou não sua opinião, o que leva à necessidade deste fornecer justificativa caso não considere o 
posicionamento do comitê; c) Como os órgãos gestores estaduais veem a atuação dos comitês e compatibilizam suas decisões no processo de licenciamento.

Frente a esses questionamentos, a proposta deste trabalho, é contribuir para o entendimento da participação dos $\mathrm{CBHs}$ nos processos de licenciamento ambiental, de empreendimentos com possíveis impactos nos recursos hídricos. Utilizou-se como estudo de caso o Comitê de Bacia Hidrográfica do Rio Sorocaba e Médio Tietê e três empreendimentos que tiveram os seus processos de licenciamento ambiental apreciados pelo CBH-SMT: a proposta de construção de um aterro sanitário no município de Sorocaba; a Central de Gerenciamento Ambiental localizada no município de Iperó, hoje já em funcionamento; e a proposta de construção de uma Central de Gerenciamento Ambiental no município de Araçariguama. A localização dos empreendimentos pode ser observada na Figura 1.

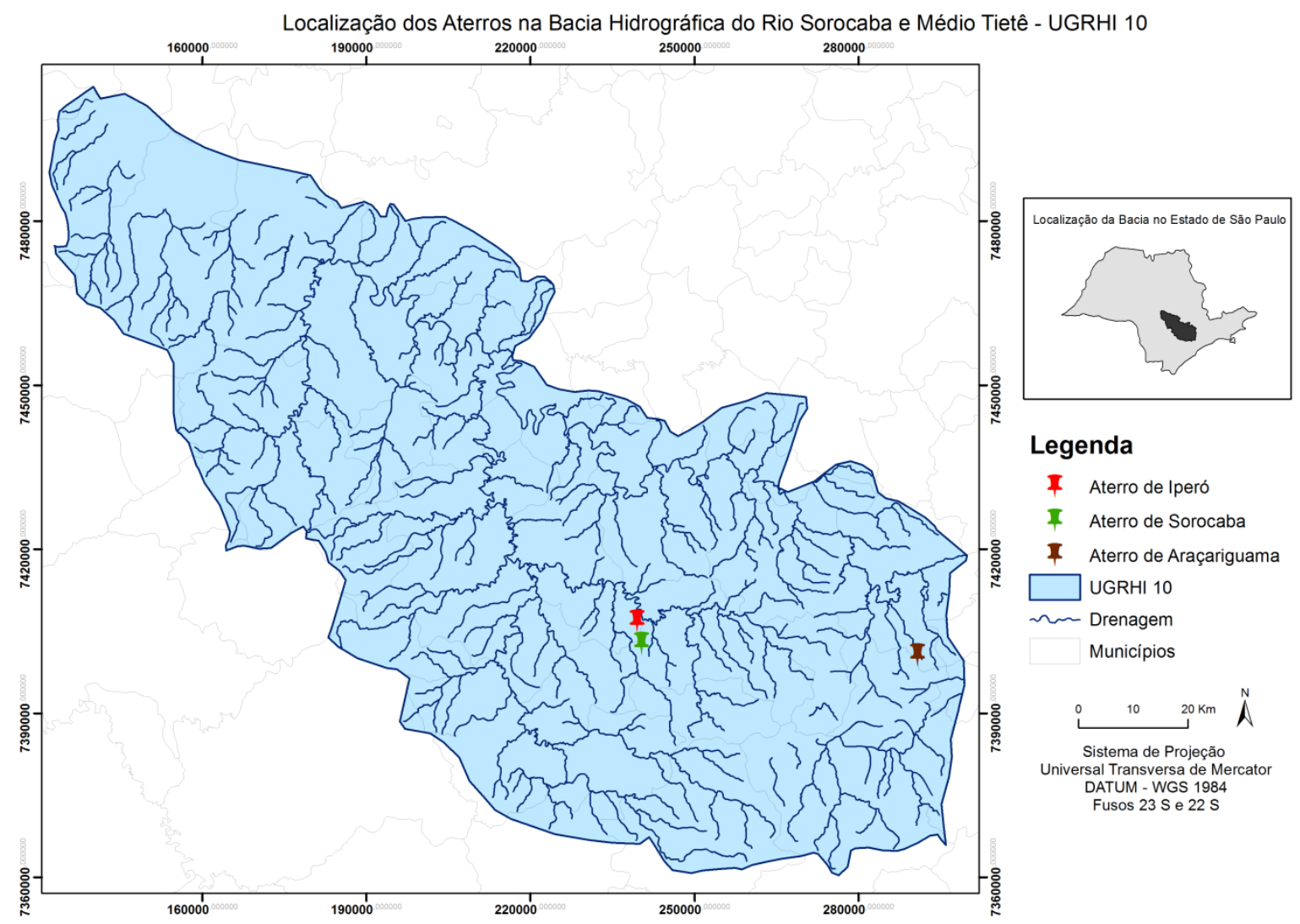

Figura 1. Localização dos aterros na bacia hidrográfica do rio Sorocaba e Médio Tietê.

Fonte: Elaborado com base nos relatórios fornecidos pelo CBH-SMT (2017).

\section{MATERIAIS E MÉTODOS}

Este trabalho utilizou o estudo de caso como estratégia para pesquisa qualitativa, baseada na análise documental de dados secundários. Yin (2001, p. 107 e 111) considera tanto a documentação quanto os registros em arquivos, duas importantes fontes de evidências: “[...] é provável que as informações documentais sejam relevantes a todos os tópicos do estudo de caso [...]. Para muitos estudos de caso, os registros em arquivo - geralmente em sua forma computadorizada - também podem ser muito importantes [...]". Para o autor Guerring, (2004, p. 342) o estudo de caso é "[...] um estudo intensivo de uma única unidade, com o propósito de compreender um grupo maior de unidades semelhantes". Desta forma, a unidade de análise escolhida para compreender melhor a participação dos comitês de bacias hidrográficas nos processos de licenciamento ambiental de empreendimentos com possíveis impactos nos recursos hídricos, foi o Comitê de Bacia Hidrográfica do Rio Sorocaba e Médio Tietê. 
Como instrumento de coleta de evidências foram explorados os pareceres técnicos de três processos de licenciamento ambiental de aterros sanitários ou centrais de gerenciamento ambiental, analisados tanto pelo CBH-SMT, como pelo órgão licenciador (Companhia Ambiental do Estado de São Paulo - CETESB ou Departamento de Avaliação de Impacto Ambiental - DAIA). Os pareceres técnicos publicados pelo comitê foram comparados aos pareceres técnicos publicados pelo órgão ambiental, com foco principal nas dimensões sociais e de proteção dos recursos hídricos. Para tanto, avaliou-se o posicionamento do órgão licenciador em relação às sugestões efetuadas pelo comitê, ou seja, se este órgão leva em consideração, argumenta e/ou incorpora de alguma forma na documentação processual do licenciamento o que foi proposto ou sugerido pelo comitê. As informações acerca dos documentos utilizados nesta pesquisa podem ser observadas na Tabela 1.

Tabela 1. Informações relevantes de cada aterro sanitário analisado bem como de seus respectivos pareceres técnicos: Localização do empreendimento; ano em que se deu entrada ao processo de licenciamento ambiental; empreendimento de caráter público ou privado; $\mathrm{n}^{\circ}$ e data oficiais de publicação do parecer técnico emitido pelo $\mathrm{CBH}-\mathrm{SMT} ; \mathrm{n}^{\circ}$ e data oficiais de publicação do parecer técnico do órgão licenciador responsável.

\begin{tabular}{llccccc}
\hline Local & Ano & $\begin{array}{c}\text { Caráter do } \\
\text { empreendimento }\end{array}$ & $\begin{array}{c}\mathbf{N}^{\mathbf{0}} \text { do parecer } \\
\text { CBH-SMT }\end{array}$ & $\begin{array}{c}\text { Data de } \\
\text { publicação } \\
\text { parecer } \\
\text { CBH-SMT }\end{array}$ & $\begin{array}{c}\text { Data de } \\
\mathbf{N}^{\mathbf{0}} \text { do parecer } \\
\text { Órgão } \\
\text { Licenciador }\end{array}$ & $\begin{array}{c}\text { publicação } \\
\text { parecer } \\
\text { Órgão } \\
\text { Licenciador }\end{array}$ \\
\hline Sorocaba-SP & 2006 & Público & $206 / 08$ & $04 / 07 / 08$ & CETESB: 005/11 & $30 / 06 / 11$ \\
Iperó - SP & 2007 & Privado & $206 / 08$ & $04 / 07 / 08$ & DAIA: $493 / 08$ & $07 / 11 / 08$ \\
Araçariguama - SP & 2010 & Privado & $262 / 11$ & $08 / 12 / 11$ & CETESB: 065/13 & $06 / 11 / 13$ \\
\hline
\end{tabular}

Fonte: Organizado a partir de documentos do CBH-SMT (2008; 2011), São Paulo (2008a) e CETESB (2011; 2013).

\section{RESULTADOS E DISCUSSÃO}

Em 2006 o CBH-SMT recebeu dois EIA/RIMAs juntos para serem analisados (um do aterro no município de Iperó/SP e outro no município de Sorocaba/SP), de forma que encaminharam para o órgão licenciador apenas um parecer técnico sobre os dois empreendimentos. Neste trabalho foram analisados e discutidos cada empreendimento separadamente: o aterro municipal de Sorocaba e a Central de Gerenciamento Ambiental de Iperó.

O primeiro Parecer Técnico analisado foi o emitido pelo CBH-SMT (206/08), referente ao aterro do município de Sorocaba/SP. O comitê utilizou critérios estabelecidos e determinados no Relatório Zero das Bacias do rio Sorocaba e Médio Tietê do ano de 2005, bem como no Plano de Bacias de 2006 (depois complementado em 2008). Este último possui 14 metas. Destas, foram destacadas oito, que se associavam diretamente com a implantação do empreendimento.

A meta 3 diz respeito à implantação e/ou ampliação e/ou adequação e/ou recuperação de sistemas de destinação final de resíduos sólidos domésticos. Em relação a essa meta, o comitê destacou que a cidade de Sorocaba/SP apresentava nota média (anos de 1997 e 2007) de IQR (Índice de Qualidade de Resíduos) igual a 8.3, o que demonstrou condições adequadas de disposição de seus resíduos domiciliares. Considerou-se sua implantação em situação prioritária, já que o aterro utilizado na época (São João) encontrava-se no limite de capacidade.

Outras metas avaliadas pelo comitê, que se relacionam à disponibilidade hídrica, foram a 4, 5 e 6, segundo as quais o Plano de Bacia indicava que a sub-bacia onde seria instalado o empreendimento encontrava-se em situação "critica" (CBH-SMT, 2008). 
Foi solicitado que o município de Sorocaba apresentasse em seu Plano Diretor Municipal políticas que conservem e protejam os mananciais de abastecimento da cidade, e os recursos hídricos em geral. Houve também a preocupação com eventuais problemas de coleta e destinação do chorume proveniente do aterro, pois havia a proximidade do empreendimento com o Rio Sorocaba e outros dois afluentes (que abastecem a região), além de poços de abastecimento público do bairro George Oetterer no município de Iperó/SP.

As metas 10 e 11 referem-se à Diversidade Biológica, considerando a cobertura vegetal de extrema importância para a proteção e conservação dos recursos hídricos. O projeto do aterro de Sorocaba/SP tinha sua localização na Zona de Amortecimento (ZA) da Floresta Nacional de Ipanema (FLONA), Unidade de Conservação da região que foi criada também com o objetivo de proteção aos recursos hídricos. Dessa forma a localização do aterro foi considerada inapropriada, pois poderia comprometer a qualidade dos recursos hídricos e dinâmica ambiental da região.

O documento recomenda que a Prefeitura de Sorocaba pesquise outras áreas além das já avaliadas e apresentadas no EIA, priorizando regiões que estejam fora da ZA da FLONA e distantes do Rio Sorocaba. Apesar de o empreendedor ter demonstrado no EIA que iria promover ações que evitariam a contaminação das águas, o comitê considerou que, nesse caso, deve-se usar o "Princípio da Precaução", já que acidentes podem acontecer, comprometendo o uso dos recursos hídricos pelos municípios à jusante do empreendimento e, de maneira direta, a disponibilidade hídrica do Rio Sorocaba.

O comitê também considerou os impactos sociais que poderiam ser causados nas populações vizinhas ao aterro como geração de odores, e criação de vetores, e conclui que mesmo considerando o empreendimento importante para a Bacia, a postura de proteção às águas mostra-se prioritária, de maneira que deveriam-se evitar ações que viriam a comprometer seu uso atual e futuro.

Dessa forma, por precaução, o CBH-SMT recomendou que a implantação do empreendimento no local proposto não fosse aprovada.

Ao se analisar o parecer técnico da CETESB (005/2011) constatou-se que após o empreendedor do aterro ter o pedido de licença prévia para instalação, o ICMBio - Instituto Chico Mendes de Biodiversidade, órgão gestor da Unidade de Conservação FLONA, emitiu um documento desfavorável à sua instalação. Como consequência, a CETESB solicitou documentos complementares à Prefeitura Municipal de Sorocaba para dar continuidade ao processo, como estudos geológicos, hidrogeológicos, entre outros. Por sua vez, a Prefeitura de Sorocaba solicitou prorrogação de prazo para apresentação das informações adicionais, no que foi atendida, embora não tenham apresentado tais informações.

Por duas vezes o ICMBio foi contrário à implantação do aterro, e dada a situação, a CETESB considerou que o empreendimento era inviável, indeferindo o pedido de licença prévia. Neste parecer do órgão licenciador não foi encontrada referência alguma ao parecer técnico apresentado pelo comitê, de forma que nenhuma de suas considerações foi citada ou considerada.

Este documento do órgão licenciador foi o único encontrado que se manifestava em relação à viabilidade ambiental do empreendimento. Na Tabela 2 é apresentada a posição de cada órgão (licenciador e comitê), com foco principal nos recursos hídricos e aspectos sociais. 
Tabela 2. Comparação das posições principais tomadas pelo CBH-SMT e órgão licenciador após a análise do EIA/RIMA do aterro Municipal da Cidade de Sorocaba/SP.

\begin{tabular}{cl}
\hline ÓRGÃO & Posição Principal \\
\hline CBH-SMT & Recomenda a não aprovação da implantação do empreendimento devido principalmente à: \\
& (i) Localização inadequada (ZA da FLONA - Ipanema); \\
& (ii) Alta capacidade de impacto aos recursos hídricos da Bacia; \\
& (iii) Possível dispersão de odor que afetem o bem estar social da população vizinha; \\
& (iv) Possível criação de Vetores que afetem a saúde da população vizinha. \\
Licenciador & Negação da Licença Prévia de implantação do empreendimento devido principalmente à: \\
CESTEB & (i) Falta de informações no EIA que não foram apresentadas posteriormente pelo \\
& (ii) Posição contrária ao empreendimento pelo ICMBio (Chefia da FLONA - Ipanema). \\
\hline
\end{tabular}

Fonte: Organizado a partir de documentos do CBH-SMT (2008) e CETESB (2011).

$\mathrm{O}$ segundo aterro que teve seus pareceres analisados, foi o localizado na cidade de Iperó/SP. O mesmo parecer técnico do CBH-SMT (206/08) considerou que o Aterro de Iperó/SP seria importante para a bacia, pois Iperó/SP corresponde a um dos cinco municípios que se encontram em condições inadequadas quanto à disposição de resíduos. Possui nota média (dados entre os anos de 1997 e 2007) de IQR igual à 5.4, o que representa uma condição inadequada de disposição de resíduos. Além disso, o comitê tinha como meta de curto prazo a adequação prioritária desses cinco municípios até o ano de 2010 (CBH-SMT, 2008).

A localização do aterro também foi considerada inadequada, pois era próxima ao Rio Sorocaba (200 m de distância), que já possuía qualidade de água crítica, e também posicionada na área de amortecimento da FLONA de Ipanema, o que levou o comitê a utilizar os mesmos argumentos, contrários, apresentados no empreendimento anterior.

Tanto a discussão do princípio da precaução, na possível contaminação das águas superficiais e subterrâneas, como os impactos sociais (odores e criação de vetores) aos bairros vizinhos também foram consideradas para o aterro de Iperó/SP, ou seja, o comitê não questionou a capacidade de gestão e operação dos aterros, já que ambos apresentaram soluções técnicas, modernas e seguras para suas implantações e operações, mas a possibilidade de ocorrência de acidentes foi considerada preocupante, pois poderia comprometer um dos principais corpos de água da bacia.

O CBH-SMT propôs que o empreendedor do aterro de Iperó/SP também buscasse alternativas locacionais fora da ZA da FLONA Ipanema, já que este se tratava de empreendimento privado e regional. O parecer técnico do comitê concluiu que a importância do empreendimento seria inferior à proteção e conservação dos recursos hídricos da bacia, e recomendou que o empreendimento não fosse aprovado no local proposto.

No parecer técnico do órgão licenciador (DAIA - 493/08), em relação a este empreendimento, considerou-se somente os impactos nos recursos hídricos e os aspectos sociais. No início do documento foram descritas todas as informações consideradas para elaboração do parecer. Dentre elas, está citada a Deliberação do CBH-SMT no 206/08, bem como o parecer $n^{\circ}$ 01, emitido pelo Gestor da FLONA de Ipanema.

Segundo o DAIA, o aterro apresenta-se como uma alternativa que irá atender à demanda da região na disposição adequada dos resíduos sólidos domiciliares, e também de resíduos industriais. A sua localização não foi questionada, pois segundo o documento apresentado pelo ICMBio da FLONA - Ipanema, não há ligação dos fragmentos florestais da UC com os remanescentes que foram encontrados na área proposta para a implantação do aterro. Assim, a posição do ICMBio foi de que o licenciamento poderia ter continuidade desde que algumas providências fossem tomadas, como: desenvolvimento de estudos que subsidiassem melhor a 
implantação e manejo de projetos florestais nos fragmentos da região do empreendimento e da FLONA; adoção de características de proteção ambiental, como ISO 9001 e 14000, seguro ambiental, obtenção de crédito de carbono; entre outras exigências (São Paulo, 2008a).

Assim a posição do DAIA foi de que para dar prosseguimento com a LI e LO (Licença prévia e Licença de Operação, respectivamente) o empreendedor deveria apresentar o andamento do atendimento às exigências feitas pela FLONA - Ipanema.

Em relação à contaminação das águas subterrâneas e superficiais o parecer técnico considerou que as informações contidas no EIA foram suficientes, desde que as propostas de proteção fossem adotadas. O EIA também apresentou um plano de monitoramento das águas, que por exigência do órgão licenciador deveria ser detalhado e conter análises de amostras que avaliem futuramente eventuais alterações.

No tópico sobre contaminação das águas superficiais o DAIA citou a manifestação do comitê, porém argumentando que a possibilidade de contaminação seria remota em função da distância do empreendimento com o Rio Sorocaba $(200 \mathrm{~m})$, e que está "em conformidade com a Norma ABNT 13.896/97 (Aterro de resíduos não perigosos - Critério para projeto, implantação e operação)" (São Paulo, 2008a, p. 40).

Este órgão indicou, por fim, a viabilidade ambiental do aterro, desde que todos os programas e medidas apresentadas no EIA/RIMA, bem como as exigências por ele propostas fossem seguidas - o que inclui, por exemplo, as exigências do ICMBio, entre outras instituições, que não o Comitê de Bacia Hidrográfica do Rio Sorocaba e Médio Tietê.

A Tabela 3 resume as considerações de cada órgão (licenciador e comitê), com foco principal nos recursos hídricos e aspectos sociais.

Tabela 3. Comparação das posições principais tomadas pelo CBH-SMT e órgão licenciador após a análise do EIA/RIMA do aterro privado com projeto de localização na cidade de Iperó/SP.

\begin{tabular}{cl}
\hline ÓRGÃO & Posição Principal \\
\hline CBH-SMT & Recomenda a não aprovação da implantação do empreendimento devido principalmente à: \\
& (i) Localização inadequada (ZA da FLONA - Ipanema); \\
& (ii) Alta capacidade de impacto aos recursos hídricos da Bacia; \\
& (iii) Possível dispersão de gases odoríferos que afetem o bem estar social da população \\
& vizinha; \\
(iv) Possível criação de Vetores que afetem a saúde da população vizinha. \\
Licenciador & Recomenda a aprovação da implantação do empreendimento devido principalmente à: \\
DAIA & (i) Localização adequada, já que o próprio ICMBio não se posicionou contra; \\
& (ii) Chances de contaminação das águas da bacia são remotas; \\
& (iii) O efeito da dispersão de gases odoríferos será pequeno; \\
& (iv) Não haverá a atração e proliferação de espécies animais que possam transmitir doenças \\
\hline
\end{tabular}

Fonte: Organizado a partir dos documentos do CBH-SMT (2008) e São Paulo (2008a).

Os últimos documentos analisados foram os do aterro com projeto de instalação na cidade de Araçariguama/SP. O parecer técnico do CBH-SMT (262/11) fez uma breve descrição do empreendimento, e além de outras informações destacou que 60\% da ADA (Área Diretamente Afetada) está localizada em APP (áreas de proteção permanente) de margens de corpo d'água e de topo de morro.

Apesar de constar no EIA/RIMA que foram estudadas sete alternativas locacionais, o CBH questionou o fato de o estudo não considerar que o local escolhido seria em uma bacia de manancial de abastecimento público.

Outras considerações dispõem sobre o aterramento de nascentes, a canalização do Ribeirão do Colégio (manancial de Araçariguama, que abastece cerca de 15 mil pessoas) para a construção de uma estação de tratamento de chorume (instalada próxima à calha do rio), 
bem como impermeabilização de parte da bacia do Ribeirão do Colégio. Essas obras poderiam reduzir a vazão do Ribeirão do Colégio ou até mesmo alterar a quantidade e qualidade das águas, podendo afetar sua captação, causar impactos à biota aquática, e, além disso, as águas subterrâneas bem como as superficiais, poderiam ser contaminadas por acidente ou escoamento de chorume (CBH-SMT, 2011).

Outro aspecto levantado pelo comitê foi que o efluente do sistema de tratamento de chorume seria despejado no Ribeirão do Colégio. Segundo o comitê, mesmo sistemas avançados de tratamento de efluentes não conseguem $100 \%$ de redução da matéria orgânica, nem mesmo eliminar toda a toxicidade do chorume, que possui contaminantes, como metais pesados, em sua composição, o que poderia levar a diminuição da qualidade do Rio.

O empreendimento previa ainda a ocupação de áreas de APP. O empreendedor considerou que essa ação é permitida por Lei, caso o empreendimento seja de utilidade pública, interesse social, ou baixo impacto ambiental (Resolução CONAMA, no 369/06). Entretanto na percepção do CBH-SMT o futuro aterro não é considerado de utilidade pública (por tratar-se de um empreendimento particular), interesse social, ou baixo impacto ambiental, não se encaixando nos critérios estabelecidos pelo CONAMA.

Neste parecer o comitê não nega a aprovação ou viabilidade ambiental do empreendimento, entretanto solicita medidas condicionantes a serem tomadas pelo empreendedor. Dentre elas, destaca-se a revisão de alternativas locacionais. Em caso de não ocorrer essa revisão, e o empreendimento vier a se estabelecer no local indicado no Estudo, o CBH-SMT requisitou vários documentos, como: concordância da concessionária dos serviços de água e esgoto do município com a instalação de um aterro sanitário na bacia hidrográfica; a apresentação de cópia do Plano de Saneamento do município em que deveria conter alternativas de abastecimento público de água; apresentação de ofícios dos órgãos competentes que autorizem a supressão de APP e do aterramento dos corpos de água; e projeto de instalação de um sistema de tratamento terciário de chorume (para eliminação de toxicidade), de forma que sigam padrões de classe 1 (sic) para serem despejados no Ribeirão do Colégio.

Já no parecer da CESTESB (065/13), órgão licenciador desse empreendimento, há a menção de vários documentos considerados, entre eles a deliberação apresentada pelo Comitê de Bacia Hidrográfica do Rio Sorocaba e Médio Tietê (262/11).

Em relação à localização escolhida pelo empreendedor, a CETESB considerou que, dentre as alternativas apresentadas no EIA, o local é o mais adequado para a implantação do empreendimento, assim como os critérios legais e ambientais foram atendidos.

Com relação às áreas de APP de vegetação nativa que seriam suprimidas, o órgão licenciador considera que o empreendedor estava em conformidade com a Lei, "por se tratar de uma obra de utilidade pública, uma vez que o empreendimento proposto refere-se a uma obra de infraestrutura de gestão de resíduos" (CETESB, 2011 p. 12), e entende que existe amparo legal para tal ação.

Outra informação contida neste parecer, é a de que o chorume não seria mais tratado em uma ETE no próprio empreendimento, e sim pela concessionária dos serviços de água e esgoto do município, que faria o transporte do mesmo para uma ETE na cidade de Barueri/SP.

Segundo o órgão, o empreendedor apresentou o documento que aprova os estudos para canalização do Ribeirão do Colégio, e que após a LO deverá ser apresentada a Outorga de Direito de Uso de recursos hídricos, que permitirá as intervenções propostas.

Na página 27 do documento a CETESB faz considerações a cerca do parecer técnico apresentado pelo comitê, mas ao contrário deste, indicou que o documento que permite estudos para a canalização do Ribeirão do Colégio foram apresentados pelo empreendedor, que o chorume terá tratamento externo por parte da SABESP, e que o município de 
Araçariguama, em parceria com a concessionária dos serviços de água e esgoto se comprometeram em construir um novo ponto de captação em outro manancial de água que se somará ao Ribeirão do Colégio no abastecimento da população de Araçariguama/SP. O órgão exigiu ainda uma cópia do instrumento que formaliza essa parceria entre a SABESP e a Prefeitura Municipal de Araçariguama na nova captação.

A Tabela 4 resume as considerações de cada órgão (licenciador e comitê), com foco principal nos recursos hídricos e aspectos sociais.

Tabela 4. Comparação das posições principais tomadas pelo CBH-SMT e órgão licenciador após a análise do EIA/RIMA do aterro privado com projeto de localização na cidade de Araçariguama/SP.

\begin{tabular}{|c|c|}
\hline ÓRGÃo & Posição Principal \\
\hline CBH-SMT & $\begin{array}{l}\text { (i) Sugestão que o empreendedor busque por alternativas locacionais; } \\
\text { (ii) Documento de concordância da SABESP com a instalação do aterro na cabeceira do } \\
\text { Ribeirão do Colégio; } \\
\text { (iii) Cópia do Plano de Saneamento do município de Araçariguama que contenham } \\
\text { alternativas de abastecimento de água; } \\
\text { (iv) Ofícios dos órgãos competentes autorizando a supressão de APP e aterro do Ribeirão } \\
\text { do Colégio; } \\
\text { (v) Projeto de instalação de sistema terciário de chorume. }\end{array}$ \\
\hline $\begin{array}{l}\text { Licenciador } \\
\text { CETESB }\end{array}$ & $\begin{array}{l}\text { (i) Localização escolhida pelo empreendedor é a mais adequada; } \\
\text { (ii) Acordo entre a SABESP e Prefeitura Municipal de Araçariguama na construção de uma } \\
\text { nova rede de captação de água; } \\
\text { (iii) Há amparo legal para a supressão de APP; } \\
\text { (iv) Já existe autorização dos estudos por parte do empreendedor para que seja feita a } \\
\text { posterior canalização do Ribeirão do Colégio; } \\
\text { (v) O chorume gerado pelo aterro será tratado externamente ao local do empreendimento } \\
\text { (ETE de Barueri/SP) pela concessionária. }\end{array}$ \\
\hline
\end{tabular}

Fonte: Organizado a partir dos documentos do CBH-SMT (2011) e CETESB (2013).

\subsection{Discussão dos Resultados}

As análises permitiram averiguar que o parecere técnico emitido pelo comitê de bacia com relação à não viabilidade de implantação dos aterros nos municípios de Sorocaba e Iperó foi pouco considerado pelo órgão licenciador.

No caso do aterro de Sorocaba/SP, a sua não aprovação provavelmente se deu, por que o ICMBio se posicionou contrário à sua implantação, bem como por falta de informações relevantes que não foram apresentadas no EIA e eram necessárias para dar continuidade ao processo. Entretanto, nada se declarou a respeito das sugestões feitas pelo comitê, e da sua posição contrária à implantação do aterro.

Considerando as colocações feitas pelo comitê e que sua posição em relação à implantação de ambos os aterros foi a mesma, não se pôde entender por que houve a aprovação da implantação do aterro de Iperó/SP e a não aprovação do aterro de Sorocaba/SP, já que ambos os projetos eram próximos e na mesma região (bacia do Rio Sorocaba e na Zona de amortecimento da FLONA - Ipanema). O ICMBio também se posicionou favorável ao aterro de Iperó/SP, porém desfavorável ao aterro de Sorocaba/SP.

Essa situação fica ainda mais confusa pelo fato de o aterro de Sorocaba/SP ser para uso público, e o empreendimento de Iperó/SP ser particular, de forma que hoje o município de Sorocaba/SP paga para transportar e dispor seus resíduos (principalmente os domiciliares e urbanos) neste aterro. No ano de 2011, foram pagos à empresa $\mathrm{R} \$ 11.015 .419,18$ (onze milhões quinze mil quatrocentos e dezenove reais e dezoito centavos) para destinação dos resíduos até o aterro (Sorocaba, 2014). Nesse sentido, o caso desses dois aterros estudados poderiam ser associados a proposição de Victorino (2003), segundo a qual a legitimidade de 
alguns mecanismos de gestão dos recursos hídricos, como os comitês de bacias, pode ser comprometida por imposições vindas dos interesses econômicos.

No caso do aterro no município de Aragariguama/SP, constatou-se que as considerações feitas pelo comitê foram mais voltadas à precaução, levando em conta que esse colegiado já não pode mais posicionar-se desfavorável a implantação de um empreendimento, o que é provavelmente uma consequência da deliberação n ${ }^{\circ} 87$ do Conselho Estadual de Recursos Hídricos do Estado de São Paulo. Esta dispõe que:

Os Comitês poderão recomendar ao órgão ambiental licenciador que incorpore no parecer técnico conclusivo sobre a viabilidade técnica do empreendimento, medidas condicionantes e mitigatórias adicionais àquelas propostas no RIMA, na medida em que as mesmas minimizem os potenciais impactos sobre os recursos hídricos da Bacia, produzidos pelo empreendimento em processo de licenciamento ambiental. [...] Os comitês tem o papel de órgão consultivo no licenciamento, cabendo ao órgão licenciador a manifestação conclusiva sobre a viabilidade ambiental do empreendimento. (CRH, 2008, p. 2, grifo nosso).

Essa restrição feita pelo $\mathrm{CRH}$ indica que a proposta de descentralização da Política Nacional de recursos hídricos, que retira do Estado o monopólio da gestão de um bem público, como a água, ainda precisa de fortalecimento, principalmente nas instâncias colegiadas, que deveriam deter o poder de decisão (Cardoso, 2003).

A CESTESB ainda esclareceu em seu parecer técnico sobre o aterro de Araçariguama/SP, que considerou apenas as contribuições feitas pelo comitê que eram pertinentes, e que estavam de acordo com as metas do Plano de Bacia ou do Relatório de Situação. Observou-se que as contribuições feitas pelo $\mathrm{CBH}$ no parecer técnico deste aterro não foram justificadas textualmente com as diretrizes do Plano de Bacia do SMT, o que justifica o posicionamento da CETESB. Além disso, o órgão ambiental tem respaldo da Secretaria de Meio Ambiente de $\mathrm{SP}$, pois esta estabelece a não obrigatoriedade deste órgão em anexar o parecer técnico do comitê ao processo de licenciamento ambiental, como pode ser observado no Artigo $3^{\circ}$ da Resolução SMA 54/08:

Havendo necessidade, o CBH poderá sugerir que o DAIA incorpore no parecer técnico conclusivo sobre a viabilidade ambiental do empreendimento, medidas mitigatórias adicionais àquelas propostas no EIA e no RIMA, na medida em que as mesmas comprovadamente minimizem os potenciais impactos sobre os recursos hídricos da Bacia, produzidos pelo empreendimento em processo de licenciamento ambiental. (São Paulo, 2008b, p. 1, grifo nosso).

A análise crítica dos resultados sugere que o poder do comitê é minimizado nas análises de EIA, se comparado à proposta de gestão descentralizada e democrática das águas no Brasil. A redução deste poder pode levar a apatia do sistema, pois os atores participantes do colegiado não conseguem ver o resultado de seus esforços. Essas ações podem ser consideradas como uma estratégia de negação de participação nas tomadas de decisão, que ao invés de serem negadas frontalmente, apenas têm suas competências limitadas (Cardoso, 2003).

Assim sendo, as contribuições do Comitê do Rio Sorocaba e Médio Tietê, nos processos de licenciamento ambiental aqui analisados, parecem ainda ser pequenas. Pedro Jacobi (2006) considera que frequentemente os conselhos consultivos e deliberativos são instâncias bastante formais, que ainda não conseguem influenciar nos processos de decisão. Tatagiba (2005 p. 
210) promoveu uma revisão da literatura atual, acerca do poder de colegiados, e sugere que "os conselhos não estão cumprindo sua vocação deliberativa".

Os comitês, entretanto, podem estar contribuindo para inquietação da população e estimulando seu protagonismo nas tomadas de decisão. Vários sites e blogs (G1 Sorocaba e Jundiaí; Defenda o Ribeirão do Colégio; Gazeta de Araçariguama, Cruzeiro do Sul) postaram matérias e notícias que discutem a implantação do Aterro de Araçariguama, e em sua maioria alegam que a população mostra posição contrária ao empreendimento. Para Cardoso (2003 p. 41) "não cabe dúvida que os comitês já estão contribuindo para fortalecer o papel dos diversos atores sociais na discussão e criação de políticas públicas que contemplem os interesses de uma camada maior da população".

Pois se a ideia central da Política Brasileira de gestão de recursos hídricos é promover uma gestão descentralizada, participativa, e democraticamente justa, os comitês devem se fortalecer, e atuar como um instrumento de tomada de decisão deliberativa e não apenas como um estimulador da população.

De fato não está previsto em Lei a obrigatoriedade do órgão licenciador em acatar ou utilizar as considerações elaboradas pelos Comitês. Entretanto, estes órgãos poderiam apresentar aos comitês uma devolutiva após o recebimento dos pareceres técnicos, que justifiquem o seu posicionamento em acatar ou não essas considerações. Além disso, sabe-se que os comitês contam com a participação de um representante Estadual do próprio órgão ambiental em seu colegiado. Dessa forma, sugere-se que estes representantes participem ativamente das Câmaras Técnicas voltadas para as análises de viabilidade ambiental de empreendimentos dentro das bacias. Estas ações poderiam aproximar as entidades, a comunicação entre elas e até mesmo maximizar o poder dos comitês nesses processos. Para Empinotti et al. (2016, p. 71):

Toda boa comunicação interna e externa, particularmente quando espontânea, franca e rápida, resulta em um clima de confiança entre os participantes de um sistema de gestão com controle social. O maior desafio é de credibilidade e a necessidade de acordos que garantam a efetiva implementação dos princípios da política, para garantir os interesses e demandas das comunidades $[\ldots]$

Um estudo feito por Alvin e Ronca (2007), que utilizou o Comitê do Alto Tietê de São Paulo como caso, apresentou resultados que também identificaram uma dificuldade desta entidade em unir os seus setores e atores para a resolução de conflitos e interesses na gestão dos recursos hídricos. Para os autores, somente os esforços e ações do comitê não são suficientes:

[...] embora a pesquisa tenha identificado um esforço relevante desse fórum em agregar setores, instâncias e atores com a finalidade de equacionar os conflitos relacionados aos recursos hídricos, sabe-se que as soluções não necessariamente dependem somente de suas ações. (Alvin e Ronca, 2007, p. $334)$.

\section{CONCLUSÃO}

Neste caso estudado, o impacto do comitê nos processos de licenciamento ambiental foi pequeno, traduzindo-se somente como grandes estimuladores da sociedade civil em busca de seu protagonismo. Isso pode ser o resultado de diretrizes estabelecidas por parte do Estado que minimizam a autoridade dos comitês, como, por exemplo, ao impedir que este órgão posicione-se favorável ou desfavoravelmente à viabilidade ambiental de empreendimentos em processos de licenciamento ambiental. 
A ausência de uma comunicação mais efetiva entre órgão licenciador e os comitês de bacias, também prejudica a busca por soluções que atendam aos interesses comuns da sociedade. A autonomia deliberativa nesses processos deveria ser concedida aos comitês, em conjunto ao órgão licenciador, pois o caráter consultivo dos CBHs enfraquece a sua atuação. Os CBHs têm muito a contribuir nos processos de licenciamento ambiental, pois contam com um corpo técnico e não técnico de conhecimento múltiplo e variado, de forma que o e seu posicionamento não deveria ser desconsiderado, já que as análises feitas de cada um dos processos de licenciamento ambiental despendem tempo, recursos econômicos e muitas vezes trabalho voluntário dos representantes desse importante espaço público.

\section{REFERÊNCIAS}

ALVIN, A. A. T. B.; RONCA, J. L. C. Metodologia de avaliação qualitativa das ações dos comitês de bacias com ênfase na gestão integrada: o Comitê do Alto Tietê em São Paulo. Engenharia Sanitária e Ambiental, v. 12, n. 3, 2007. http://dx.doi.org/10.1590/S141341522007000300012

BRASIL. Casa Civil. Subchefia para Assuntos Jurídicos. Lei $n^{\circ}$ 6.938, de 31 de agosto de 1981. Dispõe sobre a Política Nacional do Meio Ambiente, seus fins e mecanismos de formulação e aplicação, e dá outras providências. Diário Oficial [da] União, Brasília, 02 set. 1981.

BRASIL. Ministério do Meio Ambiente. Programa Nacional de Capacitação de gestores ambientais: licenciamento ambiental. Brasília, 2009. 90 p.

CARDOSO, M. M. L. Desafios e potencialidades dos comitês de bacias hidrográficas. Ciência e Cultura, v. 55, n. 4, p. 40-41, 2003.

CARVAlHO, J. L. Governança da água no Estado de São Paulo: um estudo de caso do comitê de bacias hidrográficas dos Rios Sorocaba e Médio Tietê. São Paulo: Universidade de São Paulo, 2011.

COMITÊ DE BACIA HIDROGRÁFICA DO RIO SOROCABA E MÉDIO TIETÊ - CBHSMT. Deliberação $\mathbf{n}^{0}$ 206/08 de 04 de agosto de 2008. Sorocaba, 2008.

COMITÊ DE BACIA HIDROGRÁFICA DO RIO SOROCABA E MÉDIO TIETÊ - CBHSMT. Deliberação no 262/11, de 08 de dezembro de 2011. Sorocaba, 2011.

COMPANHIA AMBIENTAL DO ESTADO DE SÃO PAULO - CETESB. Parecer Técnico n⿳0 065/2013. São Paulo, 2013.

COMPANHIA AMBIENTAL DO ESTADO DE SÃO PAULO - CETESB. Parecer Técnico no 005/2011. São Paulo, 2011.

CONSELHO ESTADUAL DE RECURSOS HÍDRICOS - CRH. Deliberação nº 87, DE 28 DE OUTUBRO DE 2008. São Paulo: Governo do Estado, 2008.

CONSELHO NACIONAL DO MEIO AMBIENTE - CONAMA. Resolução nº 001, de 23 de janeiro de 1986. Diário Oficial [da] União, Brasília, 17 fev. 1986.

EMPINOTTI, V. L.; JACOBI, P. R.; FRACALANZA, A. P. Transparência e a governança das águas. Estudos Avançados, v. 30, n. 88, 2016. http://dx.doi.org/10.1590/s010340142016.30880006 
GUERRING, J. What is a case study and what is it good for? American Political Science $\begin{array}{llllll}\text { Review, } & \text { v. } & 98, & \text { n. } & 2, & 2004 .\end{array}$ http://www.jstor.org/stable/4145316?seq=1\#page_scan_tab_contents

JACOBI, P. R. Participação na gestão ambiental no Brasil: os comitês de bacias hidrográficas e o desafio do fortalecimento de espaços públicos colegiados. In: ALIMONDA, H. (Comp.) Los tormentos de la matéria: aportes para una ecología política latinoamericana. Buenos Aires: CLACSO, 2006.

SÃO PAULO (Estado). Departamento de Avaliação de Impacto Ambiental. Parecer Técnico $n^{0}$ 493/2008. São Paulo: SMA, 2008.

SÃO PAULO (Estado). Secretaria de Meio Ambiente. Resolução nº54 de 30 de julho de 2008. São Paulo, 2008.

SOROCABA. Plano Municipal de Gestão Integrada de Resíduos Sólidos do Município de Sorocaba - SP. Sorocaba, 2014.

TATAGIBA, L. Conselhos gestores de políticas públicas e a democracia participativa: aprofundando o debate. Revista de Sociologia e Política, n. 25, p. 209-213, 2005. http://dx.doi.org/10.1590/S0104-44782005000200017

VICTORINO, V. I. P. Monopólio, conflito e participação pública na gestão dos recursos hídricos. Ambiente e Sociedade, v. 6, n. 2, 2003. http://dx.doi.org/10.1590/S1414753X2003000300004

YIN, R. K. Estudo de caso: planejamento e métodos. 2. ed. Porto Alegre: Bookman, 2001. 